\title{
제 58차 DAC 통계작업반 회의 결과
}

제 28차 $\mathrm{DAC}$ 통계작업반 회의가 22 개 회원국 및 옵저버들이 참석한 가운데 2007. 6.11 12 양일간 개최되었음

I. 주요 내용

\section{1. 신규 원조형태 구분안}

\section{(New Classification of Type of Aid)}

- 신규 원조형태의 구분 안은 기존의 DAC 테이 블 1에서 프로젝트, 프로그램, 기술협력(TC), 긴급원조, 식량원조, $\mathrm{NGO}$ 지원, 행정성경비, 개발인식증진비 등으로 나뉘던 것을 $(\mathrm{A})$ 프로 젝트타입지원, (B)예산지원 및 현금이전, (C) 인적교류협력[Exchange schemes], (D)소규 모지식공유, $(\mathrm{E})$ 식량원조, $(\mathrm{F})$ 인도적지원, $(\mathrm{G})$ 부채탕감, $(\mathrm{H})$ 공여국내원조 등으로 재분류 하
는 것을 골자로 함

\section{2. $\mathrm{DAC}$ 통계(집계통계)와 $\mathrm{CRS}$ 통계(건별통계) 의 통합(CRS++)}

- 통계사무국은 회원국들이 DAC통계(집계통계) 와 $\mathrm{CRS}$ 통계(건별통계)의 통합보고양식 (CRS++)체계로 2006년도 실적을 보고하도 록 권고함. 한국은 2006년 실적부터 통합보고 형식으로 9월말 이전 보고를 목표로 함

3. ODA 계상가능 국제기구 및 INGO, PPP, Network

- ODA 계상가능 국제기구리스트에 UNITAID, IFFIm, BSEC외 다수 기구들이 추가되었으며 $\mathrm{UNPKO}$ 에 대한 지원은 지원액 중 $7 \%$ 를 $\mathrm{ODA}$ 로 계상할 수 있음. 한편, $\mathrm{PBF}$ 에 대한 2006년 
도 지원액은 예외적으로 전액 계상하되 양자 간 지원으로 보고

\section{II. 건의 사항}

\section{1. 파리선언 이행성과 설문조사}

- 2006년 파리선언 모니터링을 위한 기준선 설 문조사에서 평가지표별 정확한 개념정립이 필 요하다는 다수 회원국들의 지적에 따라 이에 대한 추가 작업이 진행될 것으로 예상됨

- 해당 설문 결과자료에서 한국은 34 개국 중 3 개국에서 전체 $\mathrm{ODA}$ 중 $4 \%$ 에 해당하는 지원 실적을 가지고 평가받았는데 10 개 항목 중 기 술협력 관련지표를 제외 하고는 거의 모든 지 표들에서 공여국들 중 가장 낮은 수준의 목표 치 달성(baseline)을 나타내고, 이에 대한 대 응방안 강구가 필요할 것으로 판단

\section{2. 건별통계와 집계통계 통합보고(CRS++)}

- 금년 2006년도의 ODA 지원실적에 대한 확정 통계 보고 시 한국은 최초로 통합보고체계 $(\mathrm{CRS}++)$ 로 보고하는 것을 목표로 하고 있는 바 관련기관 간 협력이 어느 때 보다도 중요 함. 현재 $\mathrm{KOICA}$ 는 $\mathrm{CRS}++$ 기준의 시스템 재 구축 개발이 완료되었고 수출입은행의 ODA 통계보고시스템도 개선 중

\section{ODA 통계 작성 교육 실시 필요}

- $\mathrm{DAC}$ 가입을 준비하고 있는 우리 정부로서 $\mathrm{DAC}$ 차원의 $\mathrm{ODA}$ 통계가 대국민의 $\mathrm{ODA}$ 이 해 및 설득을 위해 매우 긴요하게 활용되는 원 조정책 수립 및 평가 도구인 바, $\mathrm{DAC}$ 가 적극 추진 중인 통합보고체계 도입 이후 정확한 정 보 작성 및 주요 실적의 누락 방지를 위해 국 내 각 부처 관련 기관 원조 통계 담당자들을 대상으로 한 체계적인 통계작성 교육이 긴요

\section{III. 상세 내용}

\section{1. 의장 및 부의장 선출}

- 의장직에 벨기에 Mr. Geert Deserranno, 부 의장직에 오스트리아의 Ms. Hedwig Riegler 및 일본의 Mr. Hitoshi Shoji 대표가 선출됨. 신임의장은 취임사를 통해 ODA관련 규정결 정, 원조의 투명성 및 효과성 제고 측면에서 통계작업반의 중요성을 강조하고 임기동안 지 금까지의 작업반의 전통을 이어나갈 것임을 언급

\section{2. 의제승인}

- 58차 통계작업반 회의의 의제가 원안 그대로 승인되었으며 의장은 $\mathrm{OECD}$ 주재 $\mathrm{EC}$ 대표인 
Mr. Franco Gonzato를 소개하며 통계작업반 회의의 DAC facilitator로 참여하였음을 설명

\section{2007년 2월 통계작업반 비공식 회의록 승인}

- 원조형태의 신규 분류 안, ODA 건별통계와 집계통계의 통합작업 $(\mathrm{CRS}++)$ 및 양자/다자 보고 관련 통계작성지침 보완에 대한 협의 결 과를 기록한 회의록을 이의 없이 승인하였으 나 비공식 회의의 결정은 구속력이 없음

\section{4. 원조형태구분안(New Classification of Type of Aid) 검토}

- 신규 원조형태의 구분은 기존의 DAC 테이블 1에서 프로젝트, 프로그램, 기술협력(TC), 긴 급원조, 식량원조, $\mathrm{NGO}$ 지원, 행정성 경비, 개 발인식증진비 등으로 나뉘던 것을 $(\mathrm{A})$ 프로젝 트타입지원, (B)예산지원 및 현금이전, (C)인 적교류협력[Exchange schemes], (D)소규모 지식공유, $(\mathrm{E})$ 식량원조, $(\mathrm{F})$ 인도적지원, $(\mathrm{G})$ 부 채탕감, $(\mathrm{H})$ 공여국내원조 등으로 재분류 하는 것을 골자로 하고 있음

- 사무국은 2 월회의 결과에 따라 덴마크와 영국 및 핀란드의 2006년 실적에 신규 원조형태 분 류 안을 적용해 본 결과 몇 가지 정의의 불명 확성을 보완하면 현행 원조형태 분류기준을
대체할 수 있을 것으로 판단됨을 보고함. 10월 과 11 월 이전까지 몇 회원국들의 2006년 실적 에 대한 테스트 참여 및 이후 각 원조형태 항 목에 대한 설명자료 초안 작성 작업을 2008년 1월까지 마쳐서 2008년 2월이나 3월 중에 있 을 비공식회의에서 최종 정리된 제안을 검토 할 수 있도록 할 예정임을 밝힘

- GOVNET의 담당자는 신규 분류 안이 파리선 언의 맥락에서 역량개발과 관련된 기술협력 부문의 실적을 상세 화하여 보다 효과적인 해 당 분야의 모니터링이 가능해 질 것임을 언급 하며 신규 분류작업의 중요성을 강조

- 테스트 국가로 참여했던 덴마크는 2006년 실 적에 대한 테스트 결과는 적용 가능해 보였으 나 정의의 모호함으로 인해 일부 사업의 경우 분류안의 항목 중 어디로도 구분할 수 없는 경 우들이 있었으며 국제수지관련 정보는 하위 분류안과 국제수지 구분 값이 서로 상충하는 경우도 있었음을 보고함. 그러나 원조형태의 재분류 작업의 중요성과 파리선언 이행을 위 해 필요한 작업임을 지적하고 세부 정의의 명 확성 제고를 통해 문제를 해결해 나가야 할 것 임을 언급

- 영국도 테스트 결과에 대해 덴마크와 같은 입 장을 밝혔으며, 오스트리아는 현행 원조형태 구분이 실제와는 달리 뒤쳐져 있어 재분류 작 
업이 매우 절실함을 언급하였으며, 조정이 필 요하겠지만 각 회원국들의 적극적인 참여를 통해 내년도 작업반회의에서는 결론에 도달할 수 있도록 분류 안 확정작업을 위해 노력해야 할 필요성을 강조

- 이에 각 국은 신규원조형태 구분 안 마련에 대 해 원칙적인 지지 입장을 표명하였고 스웨덴 및 캐나다는 추가적인 테스트에 참여의사를 밝힘

- 한국은 아직 $\mathrm{DAC}$ 비회원국이지만 가입을 준 비하며 통계 부문에서의 $\mathrm{DAC}$ 기준 및 가이드 라인 준수를 위해 노력하고 있음을 언급하고 한국 역시 신규 원조형태 구분 안에 대한 원칙 적으로 중요성을 공감하고 지지하는 입장을 밝힘. 단, 타 공여국들의 테스트 결과 지적에 서 나타난 바와 같이 한국의 경우 물자지원 사 업이 포함될 수 있는 구분항목이 없는 등 일부 사업에 대한 구분이 모호한 부분이 있으며 특 히 역량개발 지원사업의 경우 여러 가지 하위 항목의 요소들이 혼합되어진 형태가 있을 수 있어 항목의 정의 및 분류 가이드라인에 보완 이 필요함을 지적

- 일본과 독일은 신규 원조형태 분류안의 도입 은 중요성은 인정하나 급격한 시스템 변화를 필요로 할 것임을 지적하며 과거 자료들에 대 한 문제 및 국내 시스템 및 절차의 문제 등 행
정적인 부담이 클 수 있어 매우 신중하게 접근 해야 할 것임을 언급하여 회의적인 입장을 보 임. 프랑스도 일부 항목의 분류에 대한 반대 입장을 표명하였고 스위스도 너무 세부적인 구분은 적용이 어려움을 언급

- 2월 회의에 이어 금번 회의에서 제시된 수정 된 구분 안은 아직 각 항목들에 대한 정의작업 이 남아있는 것이므로 세부적인 문제점들은 해당 테스크 팀에서 설명자료 작성과 함께 조 정해 나가게 될 것임을 언급하고 특히 회의적 인 입장을 보인 독일, 일본, 프랑스에 대해 테 스크 팀에 함께 참여해 줄 것을 요청함. 또한 현행 구분 안이 최근의 정책 이슈들을 위한 분 석을 지원할 수 없어서 새로운 구분 안을 마련 하게 된 것임을 다시 한 번 강조하며 규모가 작은 사업들은 통합하고 너무 큰 사업들의 경 우 세분화하여 정책분석에 알맞도록 단순화하 고 명확하게 원조형태를 구분하도록 하는 것 이 목적임을 언급

- 오스트리아, 캐나다, 덴마크, 핀란드는 수정된 분류 안을 테스트 하는데 참여하기로 하였으 며, 2006년 실적을 기준으로 신규 원조형태 구분 안 테스트에 참여를 원하는 회원국은 사 무국에 6월 말 이전 연락하기로 하였고, 보완 된 구분 초안이 완성된 후에 2008년 1사분기 중 비공식 회의에서 해당 제안을 다시 검토하 기로 하였음. 2009년 실적부터 적용하는 것을 
목표로 하고 있음

※ 신규 원조형태 구분안의 프로젝트는 기존 분 류의 투자프로젝트(수원국 내 유형자본의 증 대를 목적으로 하는 사업)를 의미하지 않으 며 새로운 정의가 테스크 팀의 초안을 통해 정리될 예정임

\section{5. 원조성과요약양식(Result at a glance template)}

- 사무국은 베트남에서의 영국의 예시를 통한 원조성과 요약양식을 설명하였음. 본 양식은 $\mathrm{MDG}$, 투입자원현황, 파리선언 원조효과성지 표 성과, 수원국 분야별 총 자원 현황 및 투입 계획, 분야별 외부 원조자금 등의 요약표를 포 함하고 있음. 해당 자료는 원조흐름의 예측가 능성을 높이고 국별 성과중심의 현황분석을 가능하게 하여 투입중심에서 성과중심의 원조 정책수립을 가능하게 할 것임을 언급

- 오스트리아는 투입자원현황 부분에 총 외채 규모 자료도 추가할 것을 제안하였으며 캐나 다는 최근의 $\mathrm{ODA}$ 실적이 부채탕감으로 인해 해당 수원국에 대한 실질 원조공여액이 증가 한 것으로 왜곡된 해석이 가능함을 지적하였 음. 이에 사무국은 형태를 변경하기 보다는 주석 처리 등을 통해 최근의 부채탕감 증가 등의 이유를 제공하는 것을 제안하였고 외채 규모 자료 추가의 가능성 여부는 확인 후 반
영하기로 답변

\section{6. 예산지원(Budget Support)}

- 사무국은 베트남에 대한 일반예산지원 사업의 경우 9 개의 공여국이 해당 지원사업에 참여하 였는데 각기 정책 마커를 다르게 해석하여 실 적보고를 하였음을 예시로 들어 일반예산지원 및 섹터프로그램에 대한 정책마커 적용여부에 대한 일관된 기준적용 필요성을 언급

- 각 회원국들은 특정한 분야를 지정하지 않도 록 되어있는 일반예산지원에 대해서는 정책마 커를 적용하지 않고 있는 그룹과 일반예산지 원과 섹터프로그램에 동일하게 정책마커를 보 고하고 있는 그룹으로 나뉘었음. 공통적으로 단일한 기준의 필요성에 대해 공감

- 이에 사무국은 현재로서 공여국들 마다 내부 정치적 요구 등의 이유로 일반예산지원에 대 한 정책마커 적용여부 관련 국제적 비교 가능 한 기준을 가지기 힘든 상황임을 인정하고 관 심 있는 회원국들과 해당 이슈에 대해 비공식 적으로 토의를 진행하기로 하였음

\section{7. 다자기구에 대한, 다자기구를 통한, 다자기 구에 의한 원조실적 보고}

- 사무국은 보다 정확한 다자기구관련, 특히 
$\mathrm{UN}$ 기구들 원조실적에 대한 UN과 DAC의 차 이를 줄이기 위해 회원국들의 건별통계(CRS) 보고 시 원조수행채널코드를 사용해 줄 것을 촉구

- 대부분의 회원국들은 다자를 통한 원조실적에 대해 지역이나 분야 중 한 가지가 정해진 (earmarked) 사업인 경우 다자간지원이 아닌 양자간 지원으로 보고하고 순수한(core) 다자 기구에 대한 지원의 경우에만 다자간 지원으 로 보고하고 있음을 밝힘

- $\mathrm{EC}$ 는 $\mathrm{UN} \mathrm{ODA}$ 실적통계의 개선을 위한 $\mathrm{UN}$ 과의 협의에 참여하기로 하였고, 사무국은 타 회원국들의 참여도 환영함을 언급

※ 한국은 2006 년도 ODA 실적 보고 시 지역이 나 분야 등이 명시적인 $\mathrm{KOICA}$ 의 다자기구 를 통한 지원실적을 양자간으로 보고할 예정 이며 건별통계의 원조수행채널 코드를 활용 하여 양자간 및 다자간으로 보고되는 모든 흐름은 분석이 가능할 것임

\section{DAC 통계작성지침 Annex2 업데이트}

\section{가. 국제기구, INGO, PPP, Network 업데이트}

- BSEC (Organisation of the Black Sea Economic Cooperation)에 대한 지원은 $78 \%$
의 비율로 $\mathrm{ODA}$ 계상이 가능하고, $\mathrm{EBRD}-$ TRWB (Trust Fund for the Western Balkans) 와 MDRP (Multi-Country Demobilisation and Reintegration Program)에 대한 지원은 전액 ODA 계상 가 능한 국제기구로 원안 통과됨

- INGO 중 International Alert, IISD (International Institute for Sustainable Development), IWTC (International Women's Tribune Centre)에 대한 지원은 ODA 계상 가능, Search for Common Ground 는 제외하는 것으로 원안 통과됨

- PPP는 GAID (Global Alliance for ICT and Development), SAS (Small Arms Survey), $\mathrm{UNITAID}$ 가 ODA 계상 가능해 졌으며, Network에서는 GDN (Global Development Network)이 신규로 ODA 계상 가능한 리스트 에 포함되었음

※ UNITAID에는 한국도 참여하고 있으며 국 제빈곤퇴치기금으로 조성된 재원을 지원하 기로 결정한 바 있음

\section{나. UN 평화유지활동 ODA 계상비율}

- UN PKO 에 대한 ODA 계상비율은 7\%임. $\mathrm{ODA}$ 계상 대상이 되는 UN평화유지활동 지 
역은 콩고(민), 코트디부아르, 아이티, 라이베 리아, 수단, 레바논, 서부사하라, 그루지아, 코 소보, 에티오피아, 동티모르 등 총 11 개 지역 임. Truce Supervision, 인도/파키스탄, 사이 프러스, $\mathrm{UNDOF}$ 등은 순수 군사목적이거나 수원국 리스트 외 지역으로 ODA 계상에서 제 외됨

- 또한 계상 가능한 활동에는 인도적지원, $\mathrm{DDR}$, 국내이주민 복귀 및 재통합작업, 성평 등 관련이슈, 개발협력 조정, 인권, 아동보호, 민간지뢰관련활동, 선거지원, 커뮤니케이션 및 대국민홍보, 민간경찰부문, 법치 및 사법시 스템 지원 등이 포함됨

\section{다. UN평화유지기금(PBF)의 ODA 적합성}

- 2006년도에 이루어진 $\mathrm{PBF}$ 의 경우에는 해당 지원금이 ODA 목적에 부합되는 데에만 쓰여 지는 것을 조건으로 공여된 것임을 인정하여 2006년도 실적에 대해서만 예외적으로 해당 실적을 전액 계상하되, 특정 목적을 명시한 지 원이므로 양자간으로 계상하도록 함

※ 한국은 2006년 $\mathrm{PBF}$ 에 3 백만불을 지원하였 으며 2006년도 ODA 확정통계 보고 시 해당 실적의 누락 없이 양자간 지원으로 전액 계 상하여야 함
- $\mathrm{ODA}$ 창구와 Non-ODA 창구를 구분할지 여 부에 관하여 뉴욕에서 추가적인 논의가 이루 어질 예정이며, 해당 논의에서 $\mathrm{PBF}$ 가 단일 한 다자기금으로 남게 결정된다면 ODA 계상 비율은 2008년 작업반회의에서 다시 논의하 게 됨

\section{라. IFFIm과 AMCs 에 대한 지원}

- IFFIm과 $\mathrm{AMCs}_{\mathrm{S}}$ 에 대한 지원도 $\mathrm{ODA}$ 계상 가 능하도록 원안 통과되었으며 해당 기구들에 대한 지원의 특성 상 지출이 이루어진 시점에 $\mathrm{ODA}$ 계상이 가능하므로 해당 기구들에 대해 서 주석을 통해 주의사항을 명시하기로 함

- 한편, 57 차 작업반회의에서 제안되었던 $\mathrm{ODA}$ 계상가능 국제기구 리스트 전체에 대한 재검 토 작업은 사무국 인력부족으로 인해 지연되 었으나 다시 작업을 재개하기로 하고 일본 $\mathrm{Mr}$ Shoji의 주도로 스위스, 캐나다가 작업그룹으 로 함께 재검토를 진행해 나갈 것임을 보고함. 검토 기준은 해당 기구의 명칭과 임무확인 그 리고 계상가능 기구 결정기준(임무, 회원국, 연간예산규모) 등의 검토임. $\mathrm{OAU}$ 및 $\mathrm{AU}$ 의 평 화유지 활동에 대한 $\mathrm{ODA}$ 계상비율 설정 가능 성에 대한 검토도 함께 이루어질 예정임. 재검 토 결과는 2008년 6월 작업반회의에서 승인 에 부쳐지게 됨 


\section{9. 파리선언의 정의 및 측정방법}

- 오스트리아와 호주의 파리선언 지표 이행결과 보고의 문제제기와 관련, 회원국들은 파리지 표 관련 데이터 수집에 어려움을 지적하고 이 행결과 설문조사의 시기적 문제점 및 월별 환 율적용, 개념정의의 명확성 부족과 해석의 일 관성 부재 문제를 언급

- 스웨덴은 파리선언의 지표는 수원국의 발전계 획 수립만을 위한 것이 아닌 공여국과의 상호 책임을 위한 것이어야 함을 언급하였고, 일본 은 프로그램 접근방식(PBA)에 대한 획일적 개 념정의의 위험성을 지적하고 보다 신중한 자 세가 필요함을 언급

- 덴마크는 용어정의의 문제를 강조하며 파리선 언에서 원조조화를 위해서는 예산지원 (Budget Support)뿐만 아니라 다른 원조형태 들도 중요한 만큼 예산지원에 대한 정의를 재 조명할 필요가 있음을 지적

- 독일은 설문조사가 ODA 예비통계와 확정통 계가 나오는 중간 시점에 이루어져서 관련 통 계자료를 수정해야 하는 문제가 발생하여 행 정적 낭비와 자료의 신뢰성 저하를 가져왔음 을 언급

- 2006년도에 실시된 파리선언 이행설문 조사
시에 수원국 현지로부터 어려움을 보고 받은 국가들은 벨기에, 독일, 호주, 오스트리아, 미 국 등이 있었고 관련 내용을 본부로 전달 받지 못했던 국가들은 덴마크, 핀란드, 스위스, 영 국, 일본 등이 있었음. 전자 그룹의 국가들은 본부 차원에서 성과 보고에 대한 지침을 전달 하는 데에 굉장히 어려움이 많았음을 피력

- 사무국은 호주와 오스트리아의 분석자료 작성 에 사의를 표명하고 해당 내용이 차기 파리선 언 이행에 관한 Joint Venture 회의에서 논의 될 것임을 설명

※ 2006년 파리선언 모니터링 결과자료에서 한 국은 34 개국 중 3 개국에서 전체 $\mathrm{ODA}$ 중 $4 \%$ 에 해당하는 지원 실적을 가지고 평가받았는 데 10 개 항목 중 기술협력 관련지표를 제외 하고는 거의 모든 지표들에서 공여국들 중 가장 낮은 수준의 목표치 달성(baseline)을 나타낸 것으로 보고되었음 (www.oecd.org/dac/effectiveness/monitoring 및 별첨자료 참조)

\section{0. 분쟁, 평화 및 치안관련 지출}

- 사무국은 지금까지 종합한 각국의 관련 보고 사례 외에 추가적인 사례 취합과 부분적인 수 정작업을 마친 후 빠른 시일 내에 해당 사례집 을 발간할 예정임을 보고함. 추가적으로 사례 
를 제공한 프랑스와 포르투갈에 사의를 표명 하였음

\section{Rio 마커 업데이트}

- Rio 마커에 대한 테스트 보고기간이 끝남에 따라 앞으로 해당 마커에 대한 보고를 지속할 지 여부와 관련하여 회원국들은 건별통계 보 고에서 마커에 대한 보고를 계속해 나가기로 합의

- 각 국은 건별통계에서 해당 마커에 대한 신뢰 성 있는 자료 수집에 어려움이 있음에 공감하 였으며 덴마크는 년 1 회 해당분야 전문가에게 의뢰하여 연간 개별실적자료에 대한 관련성 여부를 검토하도록 하여 자료를 작성하고 있 음을 언급하였음. 이에 $\mathrm{EC}$ 는 기본적으로 $\mathrm{CRS}$ 원조목적코드를 바탕으로 자동생성한 뒤 에 덴마크와 마찬가지로 전문가가 해당되지 않는 실적을 제거해 나가는 방식으로 자료를 만들고 있음을 설명함. 네덜란드 역시 덴마크 와 비슷한 방식으로 진행하고 있음을 언급

※ 한국은 2005 년 통계까지는 집계통계만 보고 하여 해당 마커에 대한 실적을 별도 보고하 지 않았으나, 2006년에 통합보고체계로 $\mathrm{ODA}$ 실적을 보고하면서 최초로 건별통계를 보고하게 되므로 관련 마커에 대한 자료작성 방안을 마련할 필요가 있음

\section{2. 청정개발체제(CDM Clean Develop- ment Mechanism)}

- 회원국들은 CDM Board에 CERs(Certified Emission Reduction Units)을 신청할 실적 을 가지고 있는 경우 사무국에 통보해 줄 것을 요청받음

- 일본은 관련 프로젝트 정보와 $\mathrm{CER}$ 의 $\mathrm{ODA}$ 계상 처리 합의에 대한 일본의 입장을 서면으 로 제출하기로 함. $\mathrm{CDM}$ 관련 $\mathrm{ODA}$ 프로젝트 에서 $\mathrm{CER}$ 을 신청할 경우 그 만큼 $\mathrm{ODA}$ 계상 실적을 차감하기로 되어있으나 일본은 해당 사업에서 $\mathrm{CER}$ 을 시장가격을 주고 구매한 경 우이므로 $\mathrm{ODA}$ 계상액을 차감하지 않는 것이 바람직하다는 입장임

\section{3. 부채 보고 개선 추진 경과 및 계획}

- 사무국은 $\mathrm{ODA}$ 부채에 대한 자료 집계작업을 재개하였으며 개별적인 회원국과의 확인을 통 해 세계은행의 데이터베이스에 개도국의 총 부채 규모 정보를 제공하기 이전에 2003년과 2004년의 자료의 차이들을 해결할 계획임을 보고 


\section{CRS 원조목적코드 변경안}

\section{가. 거버넌스}

a GOVNET은 지난 5 년간 거버넌스 분야에 대 한 실적이 $300 \%$ 정도 증가할 만큼 중요성이 커져가는 분야임에도 불구하고 $\mathrm{CRS}$ 원조목적 코드의 15000 번 대의 코드들은 민주화, 반부 패 및 이주 등의 이슈들을 반영하지 못하고 있 음을 지적하며 새로운 원조목적코드의 추가, 거버넌스 마커의 도입 등을 통해서 거버넌스 분야에 대한 모니터링 요구 증대에 부응해 나 가야 할 것임을 설명하고 회원국의 지지를 요 청함

- 이와 관련 미국, 오스트리아, 독일 대부분의 회원국들은 기본적으로 해당 분야에 대한 모 니터링 강화를 위한 노력이 필요함에는 동의 하지만 너무 많은 하위 코드들의 생성은 실질 적으로 해당 코드들에 대한 실적보고를 보장 할 수 없으므로 단순하고 실용적인 측면의 모 니터링 방안을 강구해야 할 것이며 새로운 마 커의 도입에 회의적인 입장을 표명

- 의장은 무역을 위한 원조실적 집계도 5 년 전 논의되었을 때 $\mathrm{DAC}$ 외부통계시스템을 생성 하는 것으로 추진되었다가 결국 다시 $\mathrm{OECD}$ 의 건별통계시스템으로의 통합이 논의되고 있 음을 지적하고 거버넌스 분야에 대한 모니터
링이 가능하도록 합리적인 방안을 도출해내는 데에 회원국들의 적극적인 협조를 당부

- GOVNET 테스크 팀은 2008년 작업반회의 의 검토를 위해 보완된 제안서를 작성하기로 하고 통계작업반 사무국 외에 회원국 중 $\mathrm{EC}$, 캐나다, 독일, 아일랜드 등이 함께 참여하기 로 함

\section{나. 무역을 위한 개발원조(Aid for Trade)}

- 우루과이라운드 이후 개도국의 무역참여 및 무역을 통한 개발 역량 강화가 이슈가 되었고 이후 도하 라운드에서는 $\mathrm{WTO}$ 와 $\mathrm{OECD}$ 가 공 동으로 해당 이슈 모니터링을 위한 데이터베 이스를 구축하는데 합의하여 2005년 홍콩 각 료회의에 TCBDB(Trade Capacity Building $\mathrm{DB})$ 를 통해 집계된 보고서가 제출된 바 있음. 최근 $\mathrm{DAC}$ 의 무역위원회의 및 $\mathrm{WTO} / \mathrm{OECD}$ $\mathrm{TCBDB}$ 작업그룹의 공동회의에서 $\mathrm{CRS}$ 건별 통계를 통해 무역관련 원조 실적을 집계하도 록 합의하였음. 이를 통해 2008년도부터 2007년도 실적에 대한 TCBDB 별도 보고는 없어지게 됨

- $\mathrm{CRS}$ 통계를 통한 무역관련 실적 집계를 위해 원조목적코드 중 33110 하위에 33161 Technical Barriers to Trade 와 33162 Sanitary and Phytosanitary Measures 를 
추가하고, 무역개발 마커를 도입하며, 51000 일반예산지원 하위에 51020 무역관련 조정을 추가하는 것을 제안

- 회원국들은 원조목적코드 추가에는 지지를 표 명하였으나 마커 도입에는 회의적 입장을 보 이고 지지를 보류한 국가들이 있었으며, 무역 관련 예산 지원을 무역분야 하위에 놓아야 한 다는 의견에 대해서는 일반예산지원 하위에 두는 것으로 하였음

- 2007년 실적에 대해서는 무역관련 원조실적 을 $\mathrm{CRS}$ 건별통계를 통해서 산출해야 하는 상 황인바 서면으로 후속 제안 승인을 진행하기 로 함

※ 한국은 2005년도부터 제네바 대표부의 요청 에 따라 KOICA에서 $\mathrm{TCB}$ 실적자료를 $\mathrm{DAC}$ 및 $\mathrm{WTO}$ 에 제출하고 있으며 별도 보고가 필 요 없는 2007년도 실적부터는 건별통계를 통해서 해당 실적이 보고될 수 있도록 향후 조치가 필요함

\section{다. 전염성질병}

- $\mathrm{MDG}$ 에 명시된 말라리아와 결핵과 관련된 지 원 실적 모니터링을 위해 원조목적코드 중 12250 하위에 12262 말라리아 컨트롤 12263 결핵 컨트롤 코드를 추가하는 데에는 합의하
였고, 혼란을 줄이기 위해 12250 의 설명에 성 전염병을 제외함을 명시적으로 포함시키기로 함. 한편, 아동보건 부문의 실적 추적을 위해 사업설명부분에 "Child Health" 라는 키워드 를 사용하기로 한 것과 관련 회의적 의견이 있 었으나 권고사항으로 우선적 시행 후 1년 뒤 다시 검토하기로 함

\section{UNAIDS}

- UNAIDS는 매년 5월 G8 보고를 위해 분기별 실적자료를 통해 전년도 지출실적과 향후 계 획된 지원계획내용을 $\mathrm{CRS}$ 건별통계에서 얻고 자 희망함을 보고함

- 회원국들은 요청한 자료에 대해 분기별로 또 한 5 월까지 해당 자료를 제공하는 데에는 어 려움이 있음을 언급하고 HIV/AIDS 코드를 예방과 치료로 나누는 것은 유용할 것으로 보 았으며 좀 더 진전된 관련 제안은 향후 회의에 서 다루기로 함

\section{6. 원조수행 채널코드(Channel of delivery} codes)

- 네덜란드는 DAC 통계작성지침의 Annex 2 와 $\mathrm{CRS}$ 통계작성지침의 Annex 6 에 차이를 조 정하여 통합통계보고체계의 원조수행 채널코 드를 단일화 하고 해당 코드를 6자리 코드로 
개선하는 방안을 제안

- 개별코드를 부여하는 것과 제안과 같이 코드 자체를 변경하는 데 대해서는 회의적인 입장 을 보임. 한국 역시 하나의 국제기구 리스트를 만드는 데에는 지지 입장을 표명하고 단, 이미 합의 된 바 있는 통합보고체계 상의 코드 리스 트를 기초로 신규 통계시스템을 구축하고 있 어 코드 자체의 변경 및 코드 자리수의 변경은 신중히 결정해야할 입장임을 밝힘. 이에 단일 리스트 통합은 추진하되 제안된 코드로 변경 하는 것이 아닌 기존 $\mathrm{CRS}++$ 지침의 코드리스 트를 기초로 활용하기로 함

- 본 논의는 공식회의 이후 13 일(수) 워크샵에서 재논의되었으며 한국의 요청에 따라 코드리스 트 단일화에 따른 $\mathrm{CRS}++$ 지침 중 해당 리스 트의 변경사항은 사무국에서 회원국들에 별도 공지를 통해 전달하기로 함

\section{7. 집계통계와 건별통계의 통합} (Convergence)

- 사무국은 통합보고체계(CRS++)의 테스트 단 계에서 실적산출 단계로의 추진 로드맵을 제 시하였음. 구체적 논의는 13 일 워크샵으로 대 체하기로 함

- 13 일 워크샵에서 오스트리아, 벨기에, 미국은
이미 통합작업이 완료된 상태이며 2006년도 실적 자료도 통합보고형식으로 보고예정임을 밝힘

- 덴마크, 호주, 스페인 등은 2006년도에 통합 보고체계의 테스트를 진행할 예정이며, 일본, 프랑스, 캐나다 등은 부분적으로 추진 및 준비 중임을 밝힘. 뉴질랜드, 노르웨이, $\mathrm{EC}$, 독일, 네덜란드, 한국은 통합작업을 추진 중이며 2006년 실적에 대해서 CRS++ 형태로 보고 예정임을 표명함

※ 한국은 2006년도 실적에 대한 ODA 확정통 계 보고 시 통합보고체계(CRS++)에 따라 보 고하는 것을 목표로 준비 중임. KOICA는 2 월 회의 시 2005 년도 KOICA의 실적을 대상 으로 테스트를 수행했음. 수출입은행에서도 $\mathrm{CRS}++$ 보고시스템 개발을 진행 중에 있으 며 관련기관간 협력 하에 2006년도 실적부 터 통합보고체계 적용을 위해 노력할 예정임

\section{8. 사적흐름(Private Flows) 보고 개선}

- $\mathrm{NGO}$ 및 기타 민간기구에 대한, $\mathrm{NGO}$ 및 기타 민간기구를 통한 원조흐름

- 사무국은 회원국들이 민간부문의 원조자금 흐 름에 대한 보고개선을 위해 각국의 해당 실적 을 재검토 해 줄 것과 해당 실적에 대한 각국 
의 보고자료 취합 방식 및 범위에 대해 서면으 로 설명 자료를 제출해 줄 것을 요청

19. 그리스의 간접교육비용 관련 통계작성지 침 변경 요청안 검토

- 그리스는 중고등학생에 대한 간접교육비용의 비율을 $\mathrm{ODA}$ 로 계상하는 것을 제안하였으나 덴마크, 뉴질랜드, 스페인, 오스트리아 등의 회원국들은 반대 입장을 표명하였고 전체적으 로 이 부분에 대한 통계작성지침을 변경하는 데에 대한 공감이 이루어 지지 않아 제안은 통 과되지 않았음

\section{OECD DAC 통계사무국 조직개편안 보고}

- 통계사무국은 원조의 새로운 변화 및 요구에 대응하기 위해 기존 조직을 개편하고 4 개의 섹션으로 재조정하였음을 보고

통계 및 모니터링부

- 실적집계섹션

- 통계정책 및 Non-DAC 공여국 통계섹션
- 원조확대(Scaling Up) 및 원조체계섹션 - IT 조정 및 지원섹션
- 사무국은 회원국들로부터 전달받은 문제점들 을 개선하기 위해 현재 진행 중인 OECD.STAT (www.oecd.org/dac/stats/idsonline) 통계시 스템 개선작업에 대해 보고하고 추가적인 개 선사항이 있을 경우 사무국으로 알려줄 것을 요청

\section{2008년 회의 일정}

- 59차 통계작업반 공식회의는 2008년 6월 12(화)-13(수) 양일 간 열리며 비공식 회의는 2008년 2월이나 3월 중 열릴 예정임

[ 자료 : 주오이시디대표부] 